Research Paper

\title{
Prognostic Role of C-Reactive Protein in Hepatocellular Carcinoma: A Systematic Review and Meta-Analysis
}

\author{
Zhiyun Zheng ${ }^{1}$, Lin Zhou ${ }^{1}$, Sheng Gao ${ }^{1}$, Zhe Yang1,2, Jia yao ${ }^{1}$, Shusen Zheng ${ }^{1,2 \bowtie}$ \\ 1. Key Lab of Multi-organ Transplantation, The First Affiliated Hospital, Zhejiang University, Hangzhou, Zhejiang, P.R. China. \\ 2. Divisin of Hepatobiliary and Pancreatic surgery, Department of Surgery, The First Affiliated Hospital, Zhejiang University, Hangzhou, \\ Zhejiang, P.R. China.
}

$\triangle$ Corresponding author: shusen zheng, Divisin of Hepatobiliary and Pancreatic surgery, Department of Surgery, The First Affiliated Hospital, Zhejiang University, No. 79 Qinchun Road, Hangzhou, Zhejiang, P. R. China, 310003. E-mail: shusenzheng@zju.edu.cn. Fax: $+86-571-87236466$.

() Ivyspring International Publisher. This is an open-access article distributed under the terms of the Creative Commons License (http://creativecommons.org/ licenses/by-nc-nd/3.0/). Reproduction is permitted for personal, noncommercial use, provided that the article is in whole, unmodified, and properly cited.

Received: 2013.02.08; Accepted: 2013.03.17; Published: 2013.04.01

\begin{abstract}
Background: C-reactive protein (CRP) which used to be a prototypical inflammatory cytokine has been identified involving in the progression of tumor-promoting inflammation. Several studies have indicated that CRP is a predictor for hepatocellular carcinoma (HCC), but the results are controversial. Methods: We conducted a systematic review of ten studies (I885 patients) to examine the association of high serum CRP expression with overall survival (OS) and recurrence-free survival (RFS) in HCC patients by meta-analysis. Moreover, the correlation between high serum CRP and tumor clinicopathological parameters was also assessed. Hazard ratio (HR) or odds ratio (OR) with its $95 \%$ confidence interval $(\mathrm{Cl})$ was used as the effect size estimate. Results: Our pooled results showed that high expression level of serum CRP ( $\geq 10 \mathrm{mg} / \mathrm{L})$ was associated with poor OS (HR: 2.15, 95\% Cl: I.76-2.63) and RFS (HR: 2.66, 95\% Cl: I.54-4.58) in HCC. Serum CRP overexpression $(\geq 10 \mathrm{mg} / \mathrm{L})$ was also significantly associated with the presence of tumor vascular invasion (OR: $3.05,95 \% \mathrm{Cl}$ : $1.79-5.23$ ), multiple tumor (OR: $2.36,95 \% \mathrm{Cl}: 1.36-4.10$ ), larger tumor size (OR: $3.4 \mathrm{I}, 95 \% \mathrm{Cl}$ : I.04-II.18), and advanced TNM stage (OR: 3.23, 95\% Cl: 2.29-4.57). In addition, serum CRP overexpression ( $\geq 10 \mathrm{mg} / \mathrm{L})$ tended to be correlated with poor differentiation (OR: 1.58, 95\% Cl: 0.74-3.39), though not significantly. Conclusion: The present systematic review and meta-analysis demonstrate that high serum level of CRP $(\geq 10 \mathrm{mg} / \mathrm{L})$ denotes a poor prognosis of patients with HCC.
\end{abstract}

Key words: C-reactive protein; hepatocellular carcinoma; prognosis; survival.

\section{Introduction}

Hepatocellular carcinoma (HCC) is the sixth most common devastating neoplasm worldwide with increasing incidence rate over the last several decades across the world [1]. Meanwhile, its third cancer-related mortality rate among varieties of cancers indicates the poor prognosis of HCC [1]. Despite the significant improvement of HCC management, including liver transplantation(LT), surgical resection, transarterial chemoembolization(TACE), radiofrequency ablation(RFA) and molecular therapy, the high fatality and low survival rate is really disap- pointing[2]. Thus, there is an urgent need for us to identify better predictive biomarkers, especially serum biomarkers for the prognosis of HCC.

C-reactive protein (CRP), named for its capacity to precipitate C-polysaccharide of Streptococcus pneumonia [3], is a prototypical acute phase protein that is mainly produced by the hepatocytes [4]. The main proinflammatory cytokine inducers of CRP in hepatic cells are the interleukins-1 (IL-1) and -6 (IL-6) and recently found -17 (IL-17) [5]. The secreated CRP circulating in the Peripheral blood is part of the soluble 
innate immune system where it plays an important role as a pattern-recognition molecule [6]. However, it is a sensitive but nonspecific systemic marker of inflammation, which means that CRP can rise dramatically in a variety of situations, including infection, trauma, burns, myocardial infarction and cancer [7]. In the last decades, the relationship between a baseline CRP and subsequent development of cancer was identified [8]. Furthermore, the significance of CRP as a predictor of survival has been demonstrated in gastrointestinal $[9,10]$, pancreatic cancer[11], renal [12], ovarian[13],lymphoma[14], myeloma bone disease [15], melanoma[16] and HCC[23]. However, as a matter of contradictory results as well as the small sample size in solitary study, the current opinion on the prognostic role of CRP in HCC is still controversial.

In this study, we attempt to conduct a systematic review and meta-analysis to estimate the prognostic significance of elevated serum CRP levels for overall survival (OS) and recurrence-free survival (RFS) among patients with HCC. In addition, the relationship between CRP expression and vascular invasion, tumor size, number, grade, stage was also examined among these pooled literatures.

\section{Material and Methods}

\section{Study objectives}

The primary endpoint was to evaluate the prognostic value of CRP expression in HCC patients regarding OS and RFS. The secondary endpoint was to assess the relation between CRP expression and the clinicopathological parameters including vascular invasion, tumor size, tumor number, tumor grade and tumor stage.

\section{Study Selection}

Two reviewers independently assessed publications for inclusion in the review. Discrepancies were resolved through discussion by the review team.

\section{Literature research}

A systematic literature search was performed using Pubmed (Medline) and Embase, the Cochrane Library and Web of Science databases. Medline was searched from 1948 and Embase from 1980 to the current date. An initial search strategy using recognised search terms ((CRP or c-reactive protein) and 'prognosis' and ('hepatocellular carcinoma' or HCC')) was conducted in October 2012 and then repeated in January 2013. A review of reference lists were also performed. No language limits were applied. Only human researches were included. Abstracts of all candidate articles were read by two independent reviewers (Zheng and Gao). Disagreements were resolved by discussion.

\section{Study inclusion/exclusion criteria}

Inclusion criteria for primary studies were as follows: (1) The diagnosis of HCC was made based on histological examination and the appropriate imaging characteristics, (2) CRP evaluation using serum based methods, and (3) correlation of CRP with OS or RFS. Studies not directly reporting hazard ratios (HRs) were allowed if data were available for statistical estimation as described below. There was no pre-specified follow-up period used to determine study inclusion. All studies were carefully evaluated to identify duplicate patient populations.

Exclusion criteria for primary studies were as follows: (1) Duplicate data or repeat analysis. Criteria used to determine duplicate populations including study period, hospital, treatment information, and any additional inclusion criteria. Journal with higher impact factor or the larger sample size would be included. (2) Literature with the sample size less than 20. (3) Non-human research.

\section{Quality assessment of primary studies}

Quality assessment was performed in each of the included studies in duplicate by independent reviewers (Zheng and Gao) using the Newcastle-Ottawa Quality Assessment Scale for cohort studies with our reasonable modifications (Table 1) [17]. This scale is an eight-item instrument that allows for assessment of patient population and selection, study comparability, follow-up, and outcome of interest. Interpretation of the scale is performed by awarding points, or 'stars', for high-quality elements. Stars are then added up and used to compare study quality in a quantitative manner.

\section{Data extraction}

We extracted data elements including: (1)demographic data regarding inclusion criteria, patient age, sex; (2) tumor data including number, size, stage, grade, vascular invasion; (3) survival data including OS and RFS;(4) CRP cut-off value, quantitative methods for CRP. Other variables including number of patients lost and reasons for patients lost during follow-up. OS was defined as the interval between the medical treatment (including liver resection, liver transplantation or transarterial chemoembolisation, etc.) and the death of patients or the last observation. RFS was measured from the date of treatment until the detection of the recurrence tumor or the last follow-up assessment. Tumor grade was 
described using the Edmondson-Steiner grading system, studies were rigorously grouped as well/moderate (I/II) or poor (III/IV) degrees of differentiation. Tumor vascular invasion was defined as presence of either macro- or microscopic vascular invasion (including portal vein invasion etc.).

Table I. Newcastle-Ottawa quality assessment scale.

Selection
(1) Representativeness of the exposed cohort
(a) Truly representative of the average HCC patients in the com-
munity*
(b) Somewhat representative of the average HCC patients in the
community *
(c) Selected group of users (e.g., nurses, volunteers)
(d) No description of the derivation of the cohort
(2) Selection of the non-exposed cohort
(a) Drawn from the same community as the exposed cohort *
(b) Drawn from a different source
(c) No description of the derivation of the non-exposed cohort
(3) Ascertainment of exposure (Proof of HCC and C-reactive protein
measurement)
(a) Secure record (e.g., surgical records) *
(b) Structured interview *
(c) Written self-report
(d) No description
(4) Demonstration that outcome of interest was not present at start
of study
(a) Yes *
(b) No
Comparability

(1) Comparability of cohorts on the basis of the design or analysis

(a) Study controls for recurrence or metastasis *

(b) Study controls for any additional factor (Age, gender, grade, alpha-fetoprotein level, etc.) *

\section{Outcome}

(1) Assessment of outcome

(a) Independent blind assessment *

(b) Record linkage *

(c) Self report

(d) No description

(2) Was follow-up long enough for outcomes to occur? (Death or recurrence)

(a) Yes (3 years) *

(b) No

(3) Adequacy of follow up of cohorts

(a) Complete follow up - all subjects accounted for *

(b) Subjects lost to follow up unlikely to introduce bias - small number lost - (25\%) follow up, or description provided of those lost) *

(c) Follow up rate $(<75 \%)$ and no description of those lost

(d) No statement

A study can be awarded a maximum of one star $\left(^{*}\right)$ for each numbered item within the Selection and Outcome categories. A maximum of two stars can be given for Comparability. Underlined and quoted phrases are provided in the scale to allow for adjustment to particular studies. Italicised phrases indicate our interpretation of the question relevant to this study.

\section{Data analysis}

Included studies were divided into two groups for analysis: those with data regarding OS and those regarding RFS. All the survival results were estimated as the hazard ratio for each trial. If possible, the hazard ratio (HR) and $95 \%$ confidence intervals $(95 \% \mathrm{CI})$ were obtained directly from each trial publication. When these datas were not directly reported, a mathematical estimation was done by calculating the necessary data according to the methods published by Parmer et al [18]. For the analysis of the relationship between high CRP expression and clinicopathological parameters, odds ratios (OR) and 95\% CI were combined as the effective value.

The heterogeneity of combined HRs was initially evaluated by Chi-square test and expressed by inconsistency index $\mathrm{I}^{2}$. The $\mathrm{I}^{2}$ statistic is defined as the percentage of variability due to heterogeneity rather than chance with values $>50 \%$ representing the possibility for substantial heterogeneity [19]. We chose the random effects model of DerSimonian and Laird (1986) for pooled analyses, as a result of a priori assumptions about the likelihood for heterogeneity. All statistical tests were two-sided and the significance level was set at $5 \%$. Assessment of publication bias was first evaluated by the begg's funnel plot, then performed for each of the pooled study groups using Egger's bias indicator test [20]. All analyses were carried out using the statistical software stata(version 12.0).

\section{Results}

According to the search strategies as described, eighty-nine primary studies were identified. Then, nineteen relevant studies were screened out for detailed evaluation through reading the titles and abstracts. As a result of further investigation, seven studies were eliminated owing to insufficient survival data; two studies[21,22] were eliminated due to the duplicate data from the same center on the basis of the exclusion criteria mentioned above (Figure 1). Finally, there were altogether ten studies including two articles relevant to high-sensitive CRP (h-CRP)[24,29] eligible for the meta-analysis (Table 2). Notably, there was one publication that involved two cohort studies [31].

The characteristics of retained studies were listed in Table 2. Among these ten studies, four studies were performed in Japan[23,24,27,32], three in Korea[26,29,30], one in Italy[26], one in Germany[28], one in Austria[31]. A total of 1885 HCC patients from eleven cohorts were included in this meta-analysis, with a median sample size of 133 patients, ranging from 38 to 466 patients. The number of male and fe- 
male patients were 1506 and 379, respectively, with mean/median age varying from 53 to 71 years. The follow-up period was at least 18 months, while eight cohorts more than 5 years. Viral hepatitis was usually reported and was available for $94.2 \%$ of patients in these cohorts. Tumor size described with a cutoff value occupied $71.6 \%$ of all the patients. Most studies set the cut-off value in $5 \mathrm{~cm}$. There were altogether 626 HCC patients reported with multiple tumors with a percentage of $33.2 \%$ of all the patients. Tumor differentiation was reported in $82 \%$ of the patients, and the number of well/moderate (I/II) or poor (III/IV) patients were 930 and 616, respectively. Tumor vascular invasion was identified in 533 HCC patients, varying from 11 to 136 patients in each cohort. Tumor stage was only reported in three cohorts. The methods used to determine the concentration of CRP including turbidimetric immunoassay, latex photometric immunoassay and ELISA. The cutoff value and detecting methods for the serum CRP were differed among these included studies. Most of these studies set a cutoff value of $10 \mathrm{mg} / \mathrm{L}$, while two studies relevant to h-CRP set a cut off value of $3 \mathrm{mg} / \mathrm{L}[24,29]$. However, we should note that in the study of Kohles $\mathrm{N}$ et al [28], we took the preoperative 75 th percentile $(12 \mathrm{mg} / \mathrm{L})$ as the cutoff value for two reasons: first, the value of 12 $\mathrm{mg} / \mathrm{L}$ was close to the majority of the included studies; second, when used the postoperative 75th percentile as a cutoff value, the CRP concentration showed great significance with the overall survival $(P=0.024)$. HRs were recorded for each study using available data or the methods described above. OS was reported in all studies, whereas RFS was only presented in three studies $[23,26,30]$. The points of study quality assessed by Newcastle-Ottawa quality assessment scale ranged from 4 to 7 (with a mean of 6). The basic feature description of these ten studies (eleven cohorts) was summarized in Table 2.

\section{Serum CRP expression and OS in HCC}

All the eleven cohorts reported the data of CRP expression and OS in HCC patients. There were only four cohorts reported with the initial treatment of surgical resection(S) $[23,25,27,29]$, two with LT [26,30], two with multiple therapy[24,32], two with TACE[28,31], one with non-surgical therapy(NS)[31]. It seemed that high CRP expression positively correlated with poor OS in nine of the ten cohorts. Further, the increased serum CRP level was significantly correlated to OS with a pooled HR estimated of 2.15 (95\% CI: 1.76-2.63. Figure 2). There was no evidence for significant heterogeneity of the eleven available cohorts $\left(\mathrm{I}^{2}=27.2 \%, P=0.186\right)$.

In the further investigation, we made some subgroup analysis. When the patients were segregated according to the choice of treatment (surgical vs non-surgical), region (east vs west), measurement of CRP (CRP vs h-CRP), maximal follow-up period (more than 5 years vs less than 5 years) for HCC, high serum concentration of CRP was also significantly correlated with OS and RFS (Table 4).

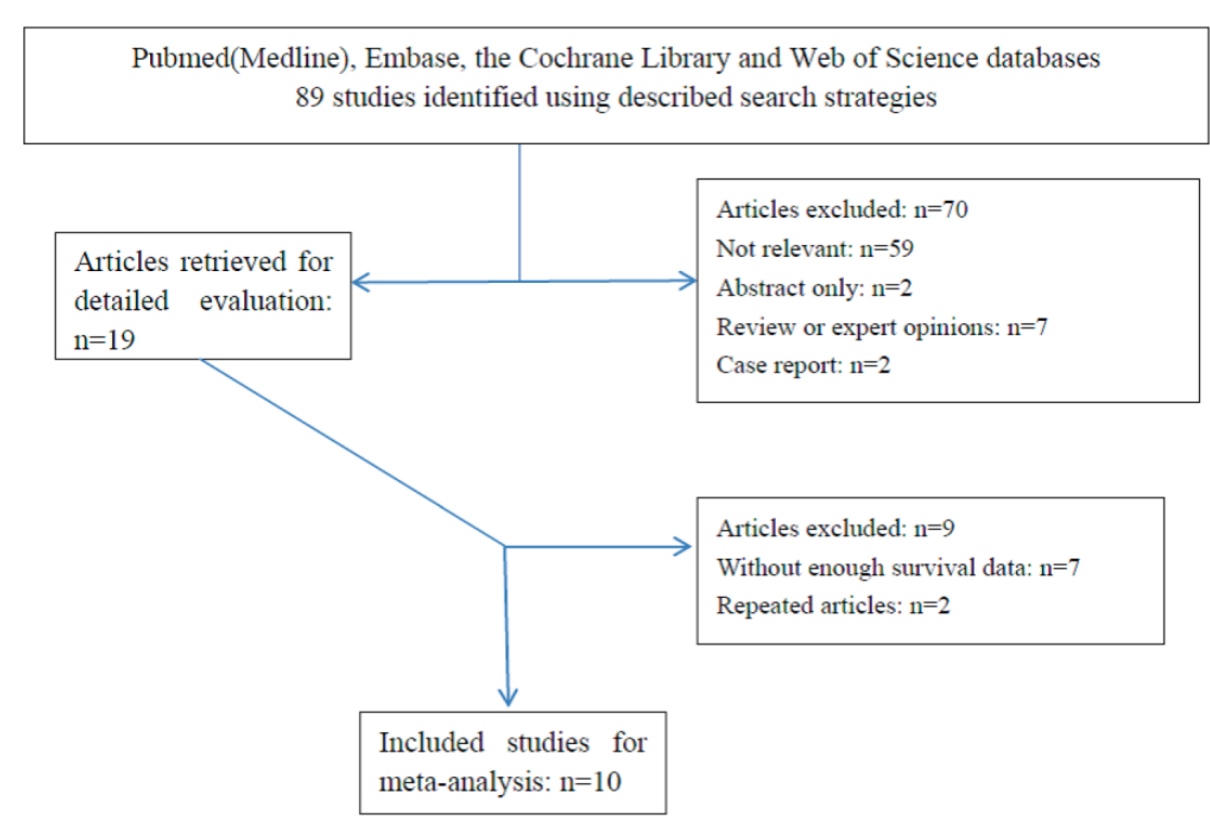

Figure I. Flow chart of the meta-analysis. 
Table 2. Summary table of the meta-analysis.

\begin{tabular}{|c|c|c|c|c|c|c|c|}
\hline Study & year & Treatment & $\begin{array}{l}\text { Sample size } \\
(\mathrm{M} / \mathrm{F}, \mathrm{n})\end{array}$ & $\begin{array}{l}\text { Mean/median } \\
\text { age (years) }\end{array}$ & $\begin{array}{l}\text { Tumor vascular } \\
\text { invasion(Yes) }\end{array}$ & $\begin{array}{l}\text { Number with large } \\
\text { tumors(cut-off used; } \\
\mathrm{cm} \text { ) }\end{array}$ & $\begin{array}{l}\text { Number with } \\
\text { Multiple prima- } \\
\text { ry tumors }\end{array}$ \\
\hline Hashimoto et $\mathrm{al}^{23}$ & 2005 & $S$ & $141(112 / 29)$ & 61.7 & 44 & NR & 56 \\
\hline Nagaoka et $\mathrm{al}^{24}$ & 2007 & Multiple therapy & $90(68 / 22)$ & 65 & 12 & NR & NR \\
\hline CHUN et $\mathrm{al}^{25}$ & 2010 & Multiple therapy & $56(48 / 8)$ & 55.7 & 14 & $40(>5)$ & 22 \\
\hline Bertuzzo et $\mathrm{al}^{26}$ & 2011 & LT & $219(186 / 33)$ & 57 & 124 & NR & NR \\
\hline Ishizuka et $\mathrm{al}^{27}$ & 2012 & $S$ & $398(316 / 82)$ & 65.1 & 133 & $270(>2)$ & 98 \\
\hline Kohles et al 28 & 2012 & TACE & $38(32 / 6)$ & 67.9 & NR & $16(>5)$ & 30 \\
\hline Jang et al29 & 2012 & NS & $110(79 / 31)$ & 58.6 & 24 & $42(>5)$ & 56 \\
\hline An et $\mathrm{al}^{30}$ & 2012 & LT & $85(64 / 21)$ & 53 & 22 & NR & 47 \\
\hline Sieghart et al $\mathrm{A}^{\mathrm{a}, 31}$ & 2012 & NS & $466(382 / 84)$ & 65 & 136 & $243(>5)$ & $187^{\mathrm{b}}$ \\
\hline Sieghart et al Ba,31 & 2012 & TACE & $149(125 / 24)$ & 66 & 11 & $50(>5)$ & $64^{\mathrm{b}}$ \\
\hline Kinoshita et $\mathrm{al}^{32}$ & 2012 & Multiple therapy & $133(95 / 38)$ & 71 & 13 & $37(\geq 5)$ & 66 \\
\hline Hashimoto et $\mathrm{al}^{23}$ & 2005 & $S$ & $141(112 / 29)$ & 61.7 & 44 & NR & 56 \\
\hline Bertuzzo et $\mathrm{al}^{26}$ & 2011 & LT & $219(186 / 33)$ & 57 & 124 & NR & NR \\
\hline Ho Jung An et al ${ }^{30}$ & 2012 & LT & $85(64 / 21)$ & 53 & 22 & NR & 47 \\
\hline
\end{tabular}

Table 3. Summary table of the meta-analysis(continue).

\begin{tabular}{|c|c|c|c|c|c|c|c|}
\hline $\begin{array}{l}\text { Tumour } \\
\text { grade } \\
\text { I/II(III/IV) }\end{array}$ & $\begin{array}{l}\text { Study } \\
\text { quality } \\
\text { points }\end{array}$ & CRP detection method & $\begin{array}{l}\text { Survival } \\
\text { analysis }\end{array}$ & Hazard ratios & $\begin{array}{l}\text { Method to determine } \\
\text { 'high' CRP cut-off } \\
\text { level }\end{array}$ & $\begin{array}{l}\text { Number of } \\
\text { patients with } \\
\text { high CRP }\end{array}$ & $\begin{array}{l}\text { summary re- } \\
\text { sults }\end{array}$ \\
\hline $105(32)$ & 7 & $\begin{array}{l}\text { latex photometric immunoassay, } \\
\text { turbidimetric immunoassay }\end{array}$ & OS & Reported in text & $\geq 10 \mathrm{mg} / \mathrm{L}$ & 22 & positive \\
\hline $25(10)$ & 7 & ELISA & OS & Reported in text & $\geq 3 \mathrm{mg} / \mathrm{L}$ & 47 & positive \\
\hline $26(30)$ & 5 & immunoturbidimetric assay & OS & Reported in text & $\geq 10 \mathrm{mg} / \mathrm{L}$ & 12 & positive \\
\hline $68(143)$ & 6 & NR & OS & Estimated & $\geq 10 \mathrm{mg} / \mathrm{L}$ & 43 & Indeterminate \\
\hline $355(24)$ & 4 & NR & OS & Estimated & $>10 \mathrm{mg} / \mathrm{L}$ & 32 & positive \\
\hline NR & 4 & turbidimetric immunoassay & OS & Estimated & $\begin{array}{l}\text { 75th percentile } \\
(\geq 12 \mathrm{mg} / \mathrm{L})\end{array}$ & 10 & Indeterminate \\
\hline NR & 5 & latex immunoturbidimetric assay & OS & Estimated & median (>3 mg/L) & 57 & positive \\
\hline NR & 7 & turbidimetric immunoassay & OS & Reported in text & $\geq 10 \mathrm{mg} / \mathrm{L}$ & 27 & positive \\
\hline $341(58)$ & 7 & NR & OS & Reported in text & ROC curve $(\geq 10 \mathrm{mg} / \mathrm{L})$ & 246 & positive \\
\hline NR & 7 & NR & OS & Reported in text & ROC curve $(\geq 10 \mathrm{mg} / \mathrm{L})$ & 43 & positive \\
\hline $10(11)$ & 7 & $\begin{array}{l}\text { latex photometric immunoassay, } \\
\text { turbidimetric immunoassay }\end{array}$ & OS & Reported in text & $\geq 10 \mathrm{mg} / \mathrm{L}$ & 27 & positive \\
\hline $105(32)$ & 7 & $\begin{array}{l}\text { latex photometric immunoassay, } \\
\text { turbidimetric immunoassay }\end{array}$ & RFS & Reported in text & $\geq 10 \mathrm{mg} / \mathrm{L}$ & 22 & positive \\
\hline $68(143)$ & 6 & NR & RFS & Estimated & $\geq 10 \mathrm{mg} / \mathrm{L}$ & 43 & Indeterminate \\
\hline NR & 7 & turbidimetric immunoassay & RFS & Reported in text & $\geq 10 \mathrm{mg} / \mathrm{L}$ & 27 & positive \\
\hline
\end{tabular}


Table 4. Subgroup analyses of pooled HR for high serum CRP expression and OS/RFS in HCC.

\begin{tabular}{|c|c|c|c|c|c|c|c|}
\hline \multirow[t]{2}{*}{ Subgroup } & \multirow{2}{*}{$\begin{array}{l}\text { No. of } \\
\text { cohorts }\end{array}$} & \multirow{2}{*}{$\begin{array}{l}\text { No. of } \\
\text { patients }\end{array}$} & \multirow[t]{2}{*}{ References } & \multirow{2}{*}{$\begin{array}{l}\text { Pooled HR } \\
(95 \% \text { CI })\end{array}$} & \multirow[t]{2}{*}{$P$ value } & \multicolumn{2}{|c|}{ Heterogeneity } \\
\hline & & & & & & $\mathrm{I}^{2}(\%)$ & P Value \\
\hline surgical resection group & 4 & 705 & $23,25,27,29$ & $2.61(1.86-3.65)$ & 0.000 & $0.0 \%$ & 0.865 \\
\hline non-surgical resection group & 7 & 1180 & $24,26,28,30,31,32$ & $2.01(1.53-2.94)$ & 0.000 & $44.2 \%$ & 0.096 \\
\hline Asian group & 7 & 1013 & $23,24,25,27,29,32$ & $2.47(1.94-3.13)$ & 0.000 & $0.0 \%$ & 0.778 \\
\hline European group & 4 & 872 & $26,28,31$ & $1.81(1.22-1.67)$ & 0.003 & $57.5 \%$ & 0.07 \\
\hline ordinary CRP group & 9 & 1685 & $23,25,26,27,28,30,31,32$ & $2.22(1.73-2.85)$ & 0.000 & $40.0 \%$ & 0.101 \\
\hline h-CRP group & 2 & 200 & 24,29 & $1.95(1.31-2.91)$ & 0.001 & $0.0 \%$ & 0.600 \\
\hline maximal follow-up period $>5$ years group & 8 & 1681 & $23,24,26,27,30,31,32$ & $2.09(1.64-2.66)$ & 0.000 & $43.0 \%$ & 0.089 \\
\hline maximal follow-up period $<5$ years group & 3 & 204 & $25,28,29$ & $2.65(1.65-4.24)$ & 0.001 & $0.0 \%$ & 0.885 \\
\hline
\end{tabular}

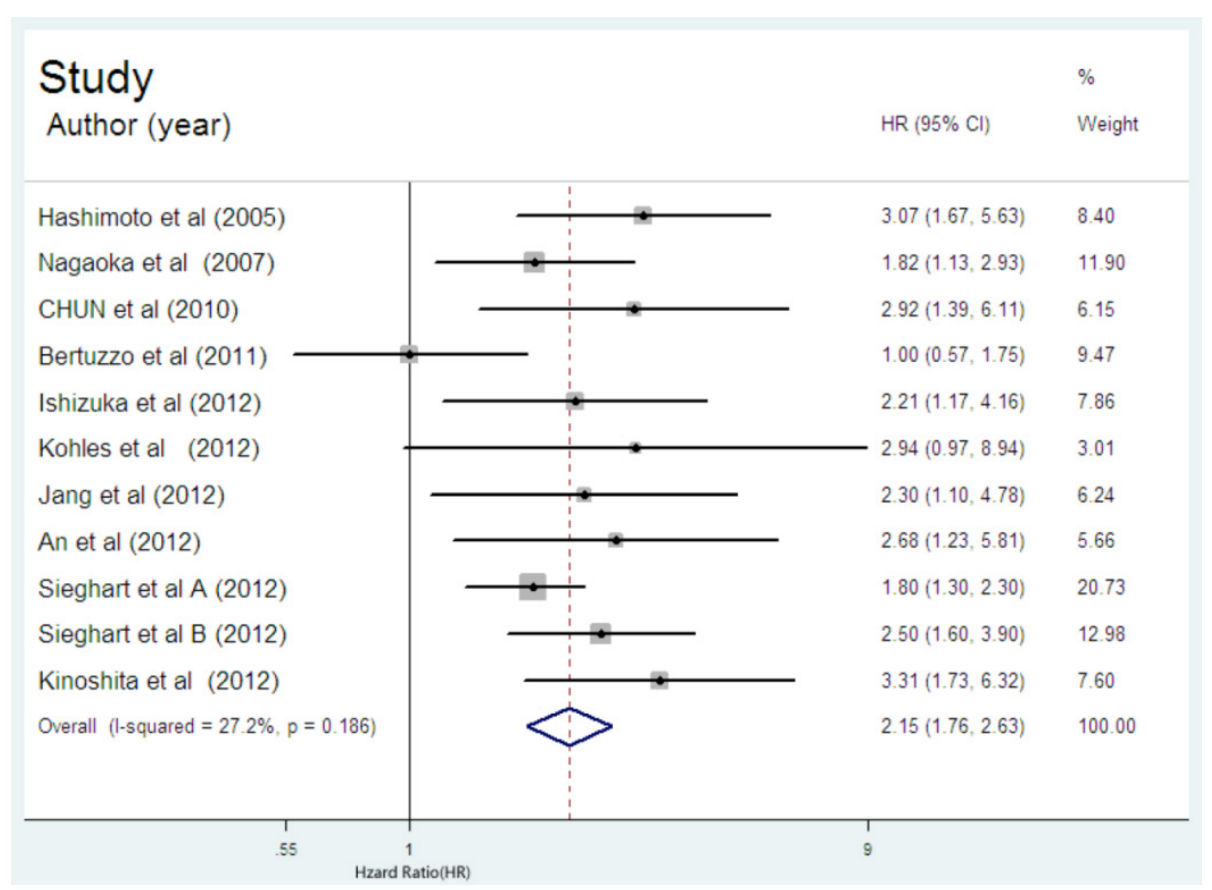

Figure 2. Forest plot of the association between high serum CRP expression and OS in HCC. Each study was shown by the name of the first author and the $\mathrm{HR}$ with $95 \% \mathrm{Cl}$ arranged by publication year. The pooled $\mathrm{HR}$ and $95 \% \mathrm{Cl}$ were also presented (according to the random effects model).

\section{Serum CRP expression and RFS in HCC}

There were only three cohort $[23,25,30]$ reported the data of CRP expression and RFS in HCC patients. The combined HR of 2.66 (95\%CI: 1.54-4.58. Figure 3) showed that the high CRP level had significant relationship with RFS in HCC patients. There was no significant heterogeneity $\left(\mathrm{I}^{2}=34.2 \%, P=0.219\right)$ of the three cohorts, either.

\section{Serum CRP expression and tumor vascular invasion in HCC}

Five studies presented the data on the serum CRP expression and vascular invasion in HCC [23,24,30-32]. Further, combined OR of $3.05(95 \%$ CI: $1.79-5.23, P=0.000$, Figure 4$)$ indicated that high se- rum CRP was associated with tumor vascular invasion in HCC. There was no significant degree of heterogeneity between the five serum studies $\left(\mathrm{I}^{2}=43.4 \%\right.$, $P=0.132)$.

\section{Serum CRP expression and tumor number in HCC}

There were five studies reported the data regarding the relation between serum CRP level and tumor number in HCC [23,29,30-32]. Among the five studies, there was one with the initial treatment of LT[30], one with surgical resection[23], two with non-surgical therapies[29,31], one with multiple therapies[32]. High serum CRP was obviously associated with tumor number in HCC with an estimated 
OR of $2.36(95 \%$ CI: $1.36-4.10, P=0.002$, Figure 5), but the heterogeneity $\left(\mathrm{I}^{2}=62.4 \%, P=0.031\right)$ was substantial. Subgroup analysis showed that the studies without the initial treatment of LT had a combined OR of 2.85(95\% CI: $1.71-4.75, P=0.000$ ) with no evident heterogeneity $\left(\mathrm{I}^{2}=49.3 \%, P=0.116\right)$.

\section{Serum CRP expression and tumor size in HCC}

Only two studies reported the data on the serum CRP expression and tumor size in HCC 29,31$]$. Both of the two studies showed the statistical significance between high serum CRP concentration and larger tumor size. The combined OR of $3.41(95 \%$ CI: 1.04-11.18, $\mathrm{p}=0.043$, Figure 6) with significant heterogeneity $\left(\mathrm{I}^{2}=83.6 \%, P=0.013\right)$ indicated the evident association between high serum CRP level and larger tumor.

\section{Serum CRP expression and tumor differentia- tion in HCC}

There were three studies provided the data regarding the serum CRP expression and tumor differentiation in $\mathrm{HCC}[23,24,32]$. None of the three studies showed the significance between high serum CRP level and poor tumor differentiation. As was expected, the pooled OR was 1.584(95\% CI: 0.739-3.394,
$P=0.237$, Figure 7$)$ with no heterogeneity $\left(\mathrm{I}^{2}=0.0 \%\right.$, $P=0.522$ ).

\section{Serum CRP expression and TNM stage in HCC}

Three studies presented the data on serum CRP expression and TNM stage in HCC [24,31,32]. Two studies indicated the statistical significance between high serum CRP expression and advanced stage. The combined OR of 3.23 (95\% CI: 2.29-4.57, $P=0.000$, Figure 8) with no heterogeneity $\left(\mathrm{I}^{2}=0.0 \%, P=0.516\right)$ strongly suggested that high serum CRP level was associated with advanced tumor stage.

\section{Publication bias}

A begg's funnel plot was presented for the visual assessment of overt publication bias for the included cohorts in serum CRP. The funnel plot shapes showed no obvious evidence of asymmetry for OS (Figure 9) and RFS (Figure 10). Then, an Egger's test was adopted for the formal evaluation (statistical significance was set at $p<0.05$ ). The $P$ value indicated that there was no significant publication bias in OS $(P=$ $0.171)$ and RFS $(P=0.801)$ among these included studies.

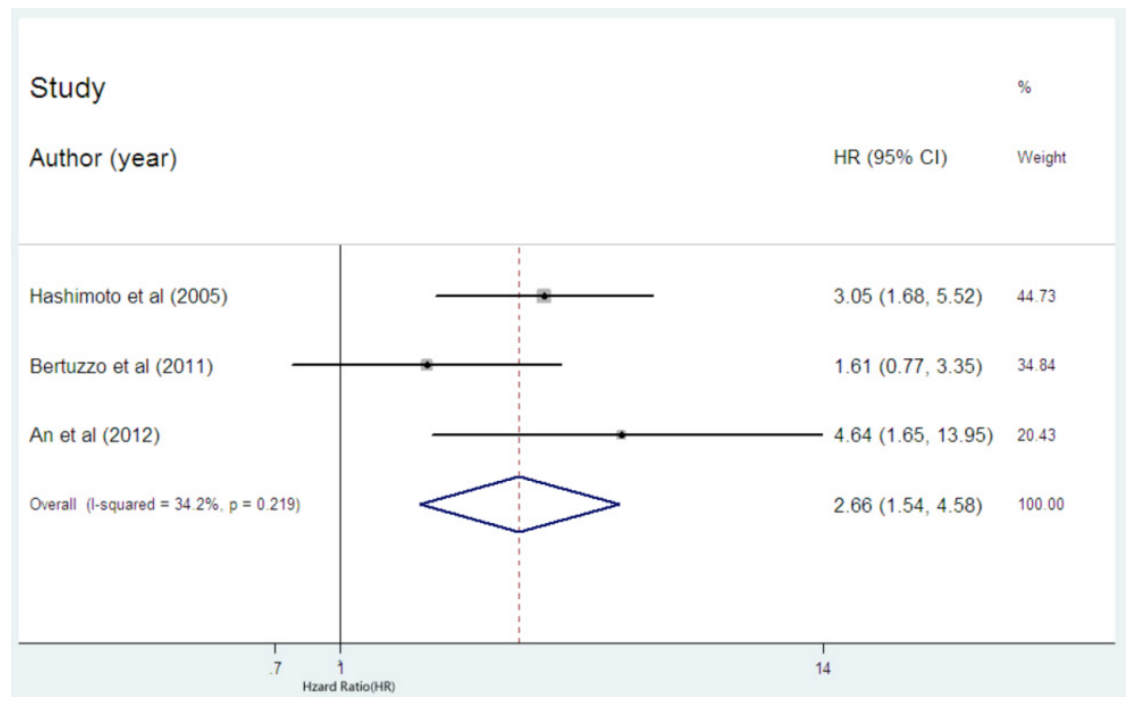

Figure 3. Forest plot of the association between high serum CRP expression and RFS in HCC. Each study was shown by the name of the first author and the $\mathrm{HR}$ with $95 \% \mathrm{Cl}$ arranged by publication year. The pooled $\mathrm{HR}$ and $95 \% \mathrm{Cl}$ were also presented (according to the random effects model). 


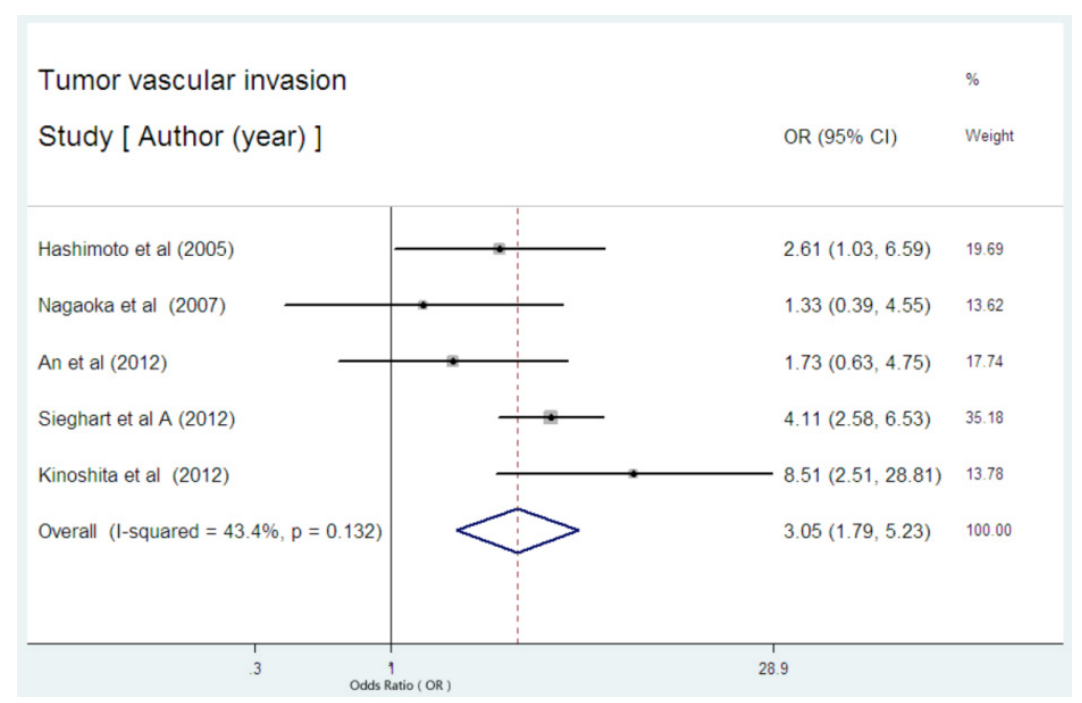

Figure 4. Forest plot of the association between high serum CRP expression and tumor vascular invasion of HCC. Each study was shown by the name of the first author and the $\mathrm{HR}$ with $95 \% \mathrm{Cl}$ arranged by publication year. The pooled OR and $95 \% \mathrm{Cl}$ were also presented (according to the random effects model).

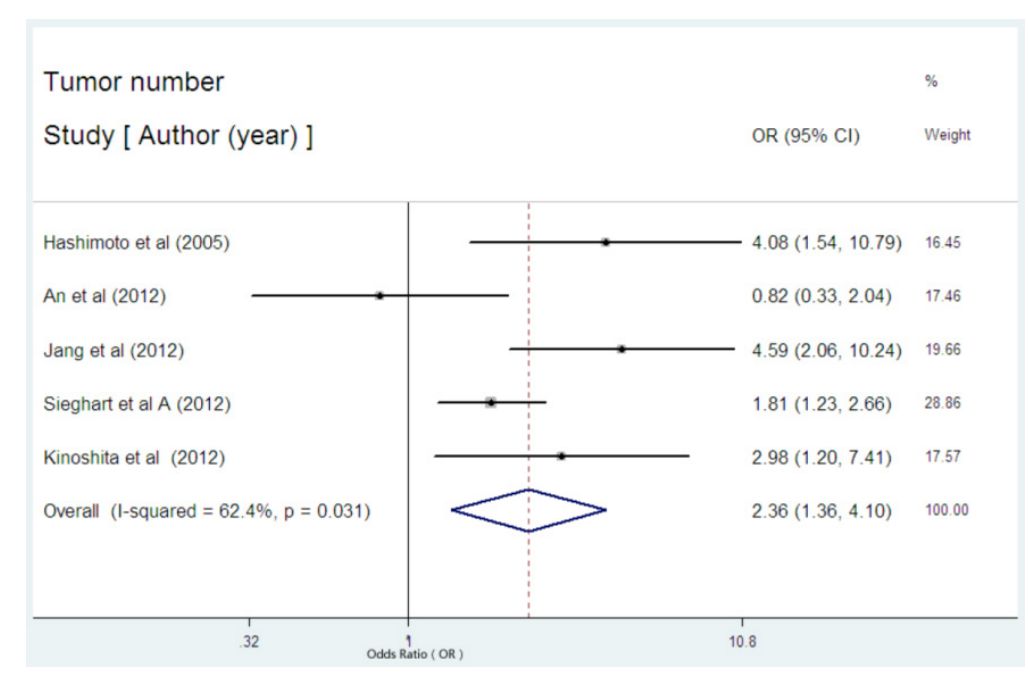

Figure 5. Forest plot of the association between high serum CRP expression and tumor number of HCC. Each study was shown by the name of the first author and the $\mathrm{HR}$ with $95 \% \mathrm{Cl}$ arranged by publication year. The pooled $\mathrm{OR}$ and $95 \% \mathrm{Cl}$ were also presented (according to the random effects model).

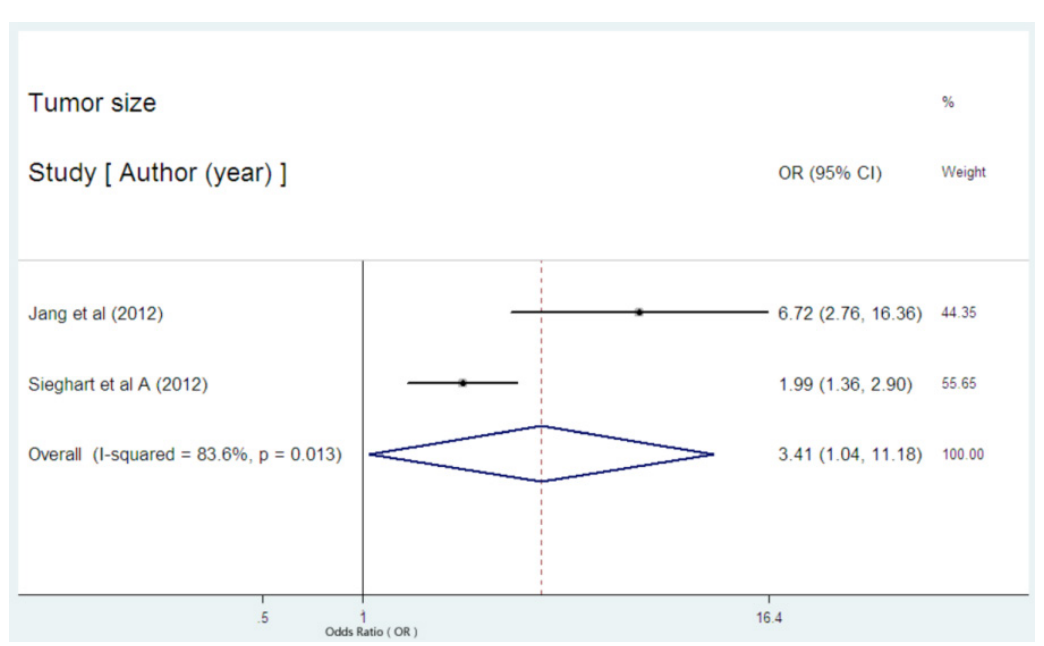

Figure 6. Forest plot of the association between high serum CRP expression and tumor size of HCC. Each study was shown by the name of the first author and the $\mathrm{HR}$ with $95 \% \mathrm{Cl}$ arranged by publication year. The pooled OR and $95 \% \mathrm{Cl}$ were also presented (according to the random effects model). 


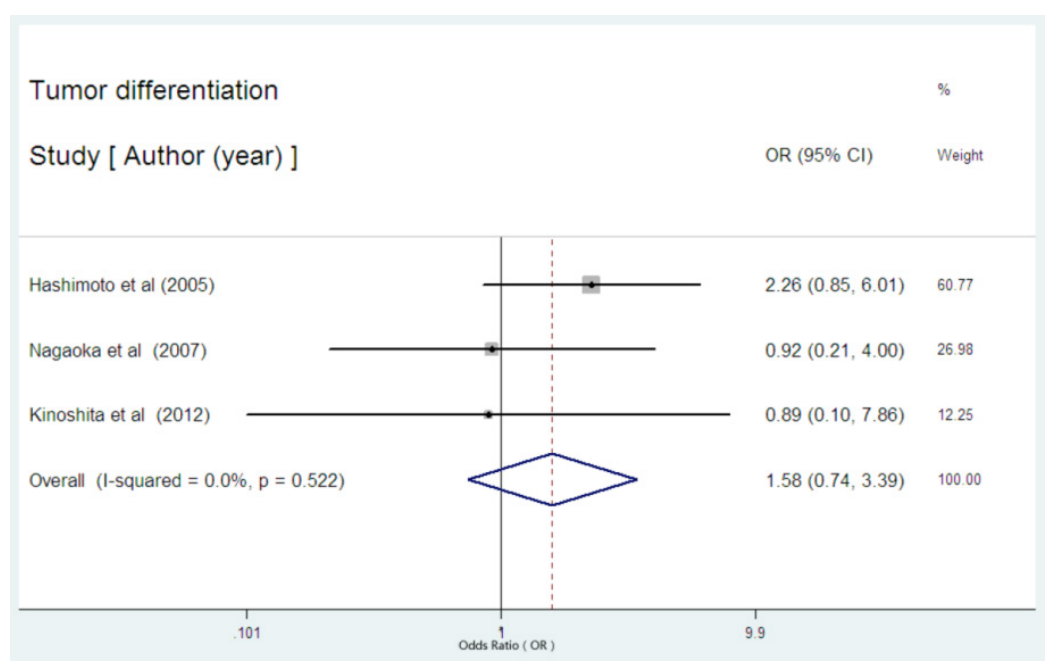

Figure 7. Forest plot of the association between high serum CRP expression and tumor differentiation of HCC. Each study was shown by the name of the first author and the $\mathrm{HR}$ with $95 \% \mathrm{Cl}$ arranged by publication year. The pooled OR and $95 \% \mathrm{Cl}$ were also presented (according to the random effects model).

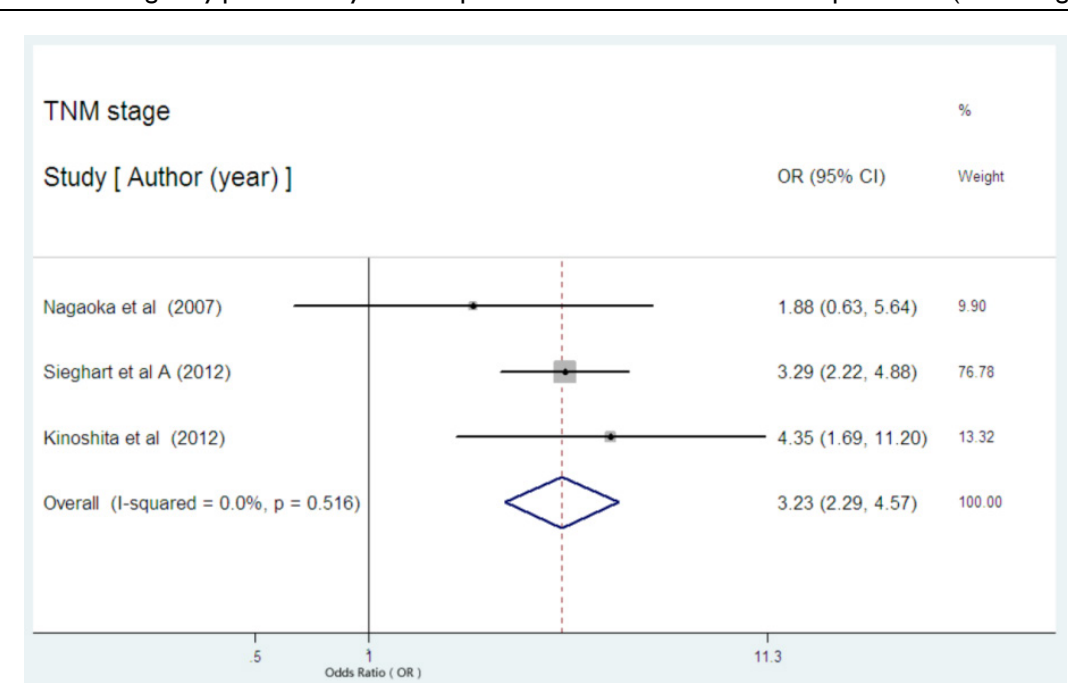

Figure 8. Forest plot of the association between high serum CRP expression and TNM stage of HCC. Each study was shown by the name of the first author and the HR with $95 \% \mathrm{Cl}$ arranged by publication year. The pooled OR and $95 \% \mathrm{Cl}$ were also presented (according to the random effects model).

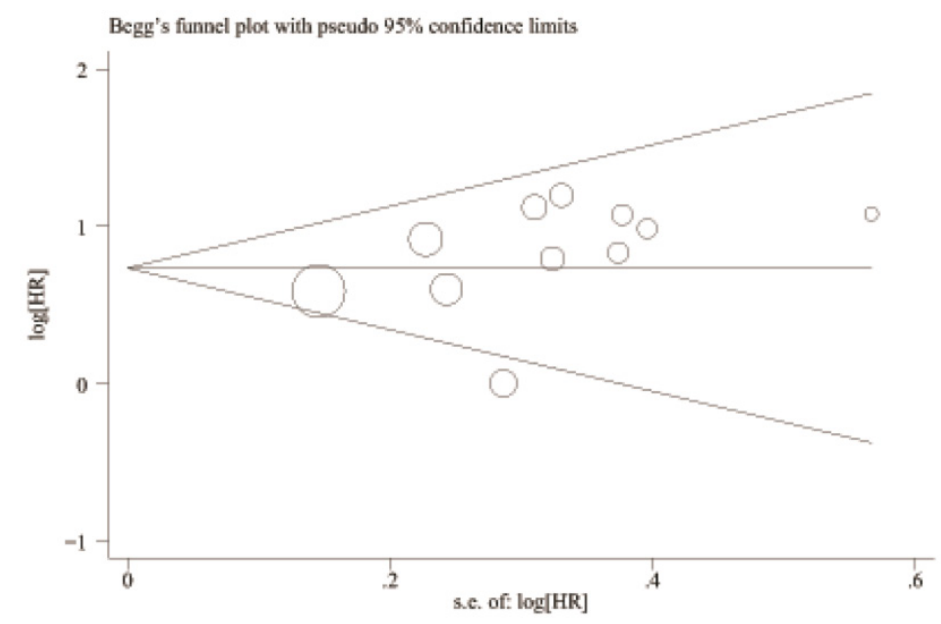

Figure 9. Begg's funnel plot for the visual assessment of overt publication bias for the included cohorts in serum CRP and OS. 


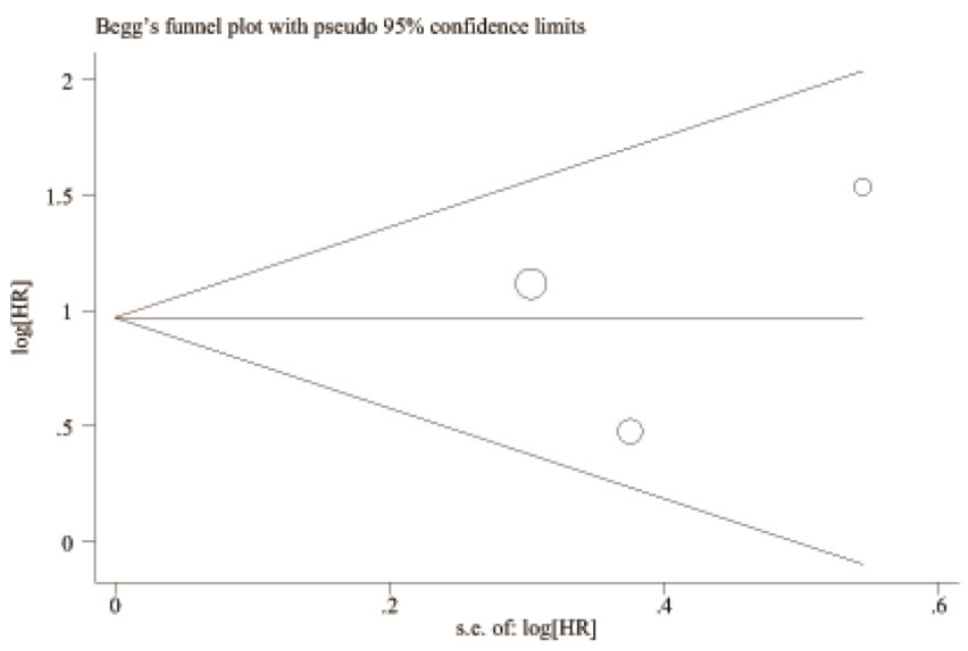

Figure 10. Begg's funnel plot for the visual assessment of overt publication bias for the included cohorts in serum CRP and RFS.

\section{Discussion}

The stratification of outcome in HCC patients is becoming increasingly important. The stratification can help guide clinical decision-making regarding therapy and better distribution of the limited medical resources such as the precious liver grafts for LT. Furthermore, patients with early stage disease and at high risk of recurrence may benefit from adjuvant therapies and risk-adjusted follow-up.

Several clinical staging systems, including the Cancer of the Liver Italian Program (CLIP) and the Barcelona Clinic Liver Cancer (BCLC) have been proposed to predict prognosis and stratify patients for therapy [33]. However, tumor recurrence was the key issue for limiting the long term survival of patients with HCC [34]. Tumor characteristics such as tumor number, size, grade, stage, especially vascular invasion were crucial for the selection of different therapies[35]. Modifications of these staging systems with the addition of plasma-based tumor markers have been proposed to improve the prognostic stratification of HCC patients, and for better selecting patients that are appropriate for certain treatment [36].

CRP has been identified for more than 80 years and was used to be a traditional inflammation marker, while its prognostic role in HCC was revealed just during the recent years. In this literature, we mainly investigated the association between the high serum CRP expression and OS as well as RFS in HCC patients. The combined HR and its 95\% CI indicated that high serum CRP expression can significantly predict the poor OS (HR=2.15, 95\% CI: 1.76-2.63) and RFS (HR=2.66, 95\% CI:1.54-4.58) in HCC. There was also no difference in analytic outcomes in these cohorts based on choice of treatment (surgical vs non-surgical), region (east vs west), measurement of CRP (CRP vs h-CRP), maximal follow-up period (more than 5 years vs less than 5 years) for HCC (data shown in Table 4 ).

Then, we also conducted a pooled analysis on the relationship of high serum CRP expression and tumor characteristics, especially for the vascular invasion which was a crucial factor for the outcome of HCC patients [35]. The result was consistent with expectation that high serum CRP expression was significantly related with the presence of vascular invasion, multiple tumor, larger tumor size, advanced TNM stage in HCC patients. Also, high serum CRP level was tended to be associated with tumor differentiation, though not significantly.

However, the molecular mechanism of tumor-related CRP elevation in HCC and other solid tumors was complicated and remained unclear. One possible explanation was the proinflammatory cytokine, IL6, which usually highly expressed in the tumor microenvironment. IL 6, the principal regulator of CRP, has been shown to be related with hepatocellular carcinoma progression [37] and metastasis [38].

Recent study indicated that inflammation with the interaction between various inflammatory cells and extracellular matrix played a crucial role in tumor microenvironment to tumorigenesis [39]. CRP was either a marker of reactive inflammation to a tumor or a marker of an on-going inflammatory process that favored tumor development [40]. However, Cervoni et al[41] found that CRP had a prognostic role in advanced cirrhotic patients(Child Pugh score $\geq 8$ ) without HCC. So it seemed that high serum CRP was just a risk factor for cirrhosis related death independent from HCC. Wolfgang Sieghart et al [31] argued 
against this presumption and extended the prognostic significance of elevated CRP to cirrhotic patients with HCC. Above all, CRP did represent an inexpensive, simple prognostic marker for patients with HCC [40].

Notably, there were some limitations for this meta-analysis. First, we searched literatures only from limited databases, the number of included studies and total sample size of included HCC patients were not large enough which might weaken the convincing power for the validity of our analysis. Second, the heterogeneity between tumor characteristics such as vascular invasion, multiple number and OS in HCC patients was significant. So was the heterogeneity between high serum CRP expression and tumor size in HCC patients. Moreover, meta-regression analysis couldn't be done to identify variables that result in heterogeneity for the reason of the limited number of primary studies. Third, the number of HCC patients from the east and west countries was 1013 and 872, respectively. However, we found that these seven included studies from Asia were only from two developed countries, Japan and Korea. As known to all, China has the largest number of HBV-related HCC patients. So we should be cautious with the representativeness of these included cohorts. Four, the methods for detecting serum CRP varied from studies, mainly including turbidimetric immunoassay, latex photometric immunoassay, and ELISA. Moreover, two studies included in this meta-analysis detected the serum h-CRP level, and the cutoff value ( 3 $\mathrm{mg} / \mathrm{L})$ was much different from other studies (10 $\mathrm{mg} / \mathrm{L}$ ). Though, subgroup analysis showed no significant difference for the h-CRP group and CRP group in OS, we should also take into consideration.

In conclusion, the present systematic review and meta-analysis demonstrated that high serum CRP expression was significantly correlated with unfavorable outcome of HCC patients. The serum CRP, a cheap, simple prognostic marker, might be warranted in stratification and selection of HCC patients for different treatments and better risk-adjusted follow-up. It might also be a potential hallmark of HCC for molecular therapy. Our meta-analysis has provided the most comprehensive quantitative evidence for the practice by far. However, this assessment needs to be further confirmed through more large prospective studies.

\section{Acknowledgements}

We thank for all the patients and clinical investigators who are involved in this meta-analysis. We also thank for the support of National S\&T Major Project (No.2012ZX10002-017) and National Basic Research Program of China (973 Program)
(No.2009CB522407).

\section{Competing interests}

The authors have declared that no competing interest exists.

\section{References}

1. Jemal A, Bray F, Center MM, et al. Global cancer statistics. CA Cancer J Clin. 2011; 61: 69-90.

2. Siegel R, Naishadham D, Jemal A. Cancer statistics. CA Cancer J Clin. 2013; 63:11-30.

3. Tillett WS, Francis Jr T. Serological reactions in pneumonia with a non-protein fraction of pneumococcus. J Exp Med.1930;52:561-71.

4. Hurlimann J, Thorbecke GJ, Hochwald GM. The liver as the site of C reactive protein formation. J Exp Med.1966; 123: 365-78.

5. Eklund CM. Proinflammatory cytokines in CRP baseline regulation. Adv Clin Chem. 2009; 48: 111-36.

6. C.A. Janeway Jr., R. Medzhitov, Innate immune recognition, Annu. Rev. Immunol. 2002;20:197-216.

7. Gabay C, Kushner I. Acute-phase proteins and other systemic responses to inflammation. N Engl J Med. 1999; 340: 448-454.

8. Erlinger T, Platz E, Rifai N, et al. C-reactive protein and the risk of incident colorectal cancer. J Am Med Assoc. 2004; 291: 585-90.

9. Nozoe T, Matsumata T, Kitamura M, et al. Significance of preoperative elevation of serum C-reactive protein as an indicator for prognosis in colorectal cancer. Am J Surg.1998; 176: 335-338.

10. Wang CY, Hsieh MJ, Chiu YC, et al. Higher serum C-reactive protein concentration and hypoalbuminemia are poor prognostic indicators in patients with esophageal cancer undergoing radiotherapy. Radiother Oncol. 2009; 92: 270-5.

11. Pine JK, Fusai KG, Young R, et al. Serum C-reactive protein concentration and the prognosis of ductal adenocarcinoma of the head of pancreas. Eur J Surg Oncol. 2009; 35: 605-10.

12. Karakiewicz PI, Hutterer GC, Trinh QD, et al. C-reactive protein is an informative predictor of renal cell carcinoma-specific mortality: a European study of 313 patients. Cancer. 2007; 110: 1241-7.

13. Hefler LA, Concin N, Hofstetter G, et al. Serum C-reactive protein as independent prognostic variable in patients with ovarian cancer. Clin Cancer Res. 2008; 14: 710-4.

14. Herishanu Y, Perry C, Braunstein R, et al. Early-mid treatment C-reactive protein level is a prognostic factor in aggressive non-Hodgkin's lymphoma. Eur J Haematol. 2007; 79: 150-4.

15. Zahlten-Hinguranage A, Goldschmidt H, Cremer FW, et al. Preoperative elevation of serum C--reactive protein is predictive for prognosis in myeloma bone disease after surgery. Br J Cancer. 2006; 95: 782-7.

16. Tartour E, Dorval T, Mosseri V, et al. Serum interleukin 6 and C-reactive protein levels correlate with resistance to IL-2 therapy and poor survival in melanoma patients. Br J Cancer. 1994; 69: 911-913.

17. Wells GA, Brodsky L, O'Connell D, et al. An Evaluation of the Newcastle Ottawa Scale: An Assessment Tool for Evaluating the Quality of Non-Randomized Studies. XI International Cochrane Colloquium Book of Abstracts.2003; XI Cochrane Colloquium Vol.O-63:26.

18. Parmar MK, Torri V, Stewart L. Extracting summary statistics to perform meta-analyses of the published literature for survival endpoints. Stat Med.1998; 17: 2815-34.

19. Higgins JPT, Thompson SG, Deeks JJ, et al. Measuring inconsistency in meta-analyses. BMJ. 2003; 327: 557-560.

20. Egger M, Davey Smith G, Schneider M, et al. Bias in metaanalysis detected by a simple, graphical test. BMJ. 1997; 315: 629-634.

21. Ishizuka M, Kubota K, Kita J, et al. Usefulness of a modified inflammation-based prognostic system for predicting postoperative mortality of patients undergoing surgery for primary hepatocellular carcinoma. J Surg Oncol. 2011;103:801-6.

22. Imai $\mathrm{N}$, Kinoshita $\mathrm{A}$, Onoda $\mathrm{H}$, et al. Persistent elevated C-reactive protein after treatment is an independent marker of a poor prognosis in patients with hepatocellular carcinoma. Clin Transl Oncol. 2012; [Epub ahead of print].

23. Hashimoto K, Ikeda $Y$, Korenaga D, et al. The impact of preoperative serum C-reactive protein on the prognosis of patients with hepatocellular carcinoma. Cancer. 2005;103:1856-64.

24. Nagaoka S, Yoshida T, Akiyoshi J, et al. Serum C-reactive protein levels predict survival in hepatocellular carcinoma. Liver Int. 2007;27:1091-7. 
25. Chun JM, Kwon HJ, Sohn J, et al. Prognostic factors after early recurrence in patients who underwent curative resection for hepatocellular carcinoma. J Surg Oncol. 2011;103:148-51.

26. Bertuzzo VR, Cescon M, Ravaioli M, et al. Analysis of factors affecting recurrence of hepatocellular carcinoma after liver transplantation with a special focus on inflammation markers. Transplantation. 2011;91:1279-85.

27. Ishizuka M, Kubota K, Kita J, et al. Impact of an inflammation-based prognostic system on patients undergoing surgery for hepatocellular carcinoma: a retrospective study of 398 Japanese patients. Am J Surg. 2012;203:101-6.

28. Kohles N, Nagel D, Jüngst D, et al. Prognostic relevance of oncological serum biomarkers in liver cancer patients undergoing transarterial chemoembolization therapy. Tumour Biol. 2012;33:33-40.

29. Jang JW, Oh BS, Kwon JH, et al. Serum interleukin-6 and C-reactive protein as a prognostic indicator in hepatocellular carcinoma. Cytokine. 2012;60:686-93.

30. An HJ, Jang JW, Bae SH, et al. Serum C-reactive protein is a useful biomarker for predicting outcomes after liver transplantation in patients with hepatocellular carcinoma. Liver Transpl. 2012;18:1406-14.

31. Sieghart W, Pinter M, Hucke F, et al. Single determination of C-reactive protein at the time of diagnosis predicts long-term outcome of patients with hepatocellular carcinoma. Hepatology. 2012;[Epub ahead of print].

32. Kinoshita A, Onoda H, Takano K, et al. Pretreatment serum C-reactive protein level predicts poor prognosis in patients with hepatocellular carcinoma. Med Oncol. 2012;29:2800-8.

33. Maluccio M, Covey A. Recent progress in understanding, diagnosing, and treating hepatocellular carcinoma. CA Cancer J Clin. 2012;62:394-9.

34. Gluer AM, Cocco N, Laurence JM, et al. Systematic review of actual 10-year survival following resection for hepatocellular carcinoma. HPB(Oxford). 2012;14:285-290.

35. Lim KC, Chow PK, Allen JC, et al. Microvascular invasion is a better predictor of tumor recurrence and overall survival following surgical resection for hepatocellular carcinoma compared to the Milan criteria. Ann Surg. 2011;254:108-13.

36. Zheng SS, $\mathrm{Xu} \mathrm{X}, \mathrm{Wu} \mathrm{J}$ et al. Liver transplantation for hepatocellular carcinoma: Hangzhou experiences. Transplantation.2008;85:1726-32.

37. Park EJ, Lee JH, Yu GY, et al. Dietary and genetic obesity promote liver inflammation and tumorigenesis by enhancing IL-6 and TNF expression. Cell. 2010;140:197-208.

38. Maeda S, Hikiba Y, Sakamoto K, et al. Ikappa B kinasebeta/nuclear factor-kappaB activation controls the development of liver metastasis by way of interleukin-6 expression. Hepatology 2009;50:1851-1860.

39. Hanahan D, Weinberg RA. Hallmarks of cancer: the next generation. Cell. 2011; 144: 646-674.

40. Dufour JF. CRP, a prognostic marker in HCC. Hepatology. 2013; [Epub ahead of print].

41. Cervoni JP, Thévenot $\mathrm{T}$, Weil $\mathrm{D}$, et al. C-reactive protein predicts short-term mortality in patients with cirrhosis. J Hepatol. 2012; 56: 1299-304. 